\title{
Utilization of Front-Face Fluorescence Spectroscopy for Analysis of Process Cheese Functionality
}

\author{
S. K. Garimella Purna, L. A. Prow, and L. E. Metzger \\ MN-SD Dairy Foods Research Center, \\ Department of Food Science and Nutrition, \\ University of Minnesota, St. Paul 55108
}

\section{ABSTRACT}

The purpose of this study was to evaluate the feasibility of front-face fluorescence spectroscopy (FFFS) to predict the meltability of process cheese spreads or products. Twenty-seven commercial samples from 3 manufacturers were used in this study. Each sample was analyzed using dynamic stress rheometry, which was used to calculate the meltability index (temperature at $\tan \delta=1$ ). Additionally, fluorescence spectra of tryptophan (excitation: $290 \mathrm{~nm}$; emission: 305 to $400 \mathrm{~nm}$ ) were collected on each sample at $20^{\circ} \mathrm{C}$ using a frontface accessory. Fluorescence spectrum for each sample consisted of an average of 36 scans (6 scans performed on 6 replicates). The spectral data set consisted of normalized and mean-centered spectra from all the samples. Multivariate statistical analysis was used to correlate spectral data with cheese meltability index as measured by dynamic stress rheometry. A prediction model was developed using partial least square regression and was calibrated using a cross-validation method. A correlation coefficient of 0.93 was obtained between fluorescence spectra and cheese meltability. The regions 335 to $350 \mathrm{~nm}$ and 385 to $400 \mathrm{~nm}$ had the highest correlation to cheese meltability. A negative correlation between the peak height of tryptophan (335 to $350 \mathrm{~nm}$ ) and cheese meltability index was observed. This correlation may be due to presence of tryptophan residues in a more hydrophobic environment in stronger emulsions as compared with a more polar environment in weak emulsions. These results indicate that the melt properties of process cheese spreads or products are related to molecular structure that can be measured using FFFS. Hence, FFFS can be used as an analysis technique to predict process cheese meltability.

(Key words: fluorescence, process cheese, multivariate statistics, meltability)

Received August 12, 2004

Accepted October 8, 2004.

Corresponding author: Lloyd E. Metzger; e-mail: lmetzger@ umn.edu.

Abbreviation key: DSR = dynamic stress rheometry, FFFS = front-face fluorescence spectroscopy, PLS = partial least square regression, PRESS $=$ prediction residual error sum square.

\section{INTRODUCTION}

Process cheese is manufactured by blending different natural cheeses and additional ingredients including emulsifying salts. The blend is then heated with continuous mixing and subsequently cooled to form a homogeneous product (Thomas, 1973). The chemistry behind process cheese manufacture can be explained by the conversion of the calcium caseinate complex (present in the natural cheese) into a hydrated gel. This is primarily achieved by addition of emulsifying salts to the formulation. Upon hydration, emulsifying salts chelate calcium, which disrupts the calcium caseinate complex (Gupta et al., 1984; Caric et al., 1985) and results in the exposure of hydrophilic and hydrophobic sections of casein. The heating and mixing steps facilitate the interaction of the exposed hydrophobic and hydrophilic sections of casein with fat and water (Marchesseau and Cuq, 1995; Ennis et al., 1998; Lee et al., 2003), producing a homogeneous melted mass (Ryan et al., 1980).

Formulation parameters such as type and age of the natural cheese, type and amount of emulsifying salt, and processing conditions such as cook temperature, cook time, and the amount of shear provided during manufacture, play a major role in controlling the emulsion formation and the resulting functional properties of process cheese (Ryan et al., 1980; Berger et al., 1998; Glenn et al., 2003). Because it is difficult to control all the formulation and processing parameters that influence process cheese functionality, manufacturers often produce batches of process cheese that deviate from desired functional properties. To get an approximate measure of the functional properties of process cheese, manufacturers typically perform one of several empirical melt tests such as the Arnott melt test (Arnott et al., 1957), Schreiber melt test (Kosikowski and Mistry, 1997), or the Tube melt test (Olson and Price, 1958). More precise and reliable, rheology-based methods such 
as dynamic stress rheometry (DSR) (Nolan et al., 1990; Ustunol et al., 1994; Sutheerawattananonda and Bastian, 1998) or modified squeeze flow rheometry (Muthukumarappan et al., 1999) may be used. Although rheological methods provide useful information on process cheese functionality, they are invasive, time consuming, and are often difficult to perform. Consequently, there is a need for new noninvasive and rapid methods that could be used to predict process cheese functionality.

As discussed earlier, process cheese functional properties are a result of molecular level interactions. Consequently, a technique that measures the interactions between casein, fat, and water at the molecular level could provide insight into the effect of formulation and processing conditions on functionality. Coincidentally, all the major cheese proteins (including casein) contain at least one residue of tryptophan (Fox, 1989; Fox and Mulvihill, 1990), a naturally occurring fluorescent substance, also called a fluorophore. The fluorescent properties of tryptophan in a hydrophobic environment are different than its fluorescent properties in a hydrophilic environment (Lackowicz, 1983). Consequently, researchers have used the emission spectra of tryptophan (305 to $400 \mathrm{~nm}$; excitation at $290 \mathrm{~nm}$ ) to evaluate the state of protein in cheese (Mazerolles et al., 2001), and to characterize the interactions between food constituents (Dufour and Riaublanc, 1997; Herbert et al., 1999; Mazerolles et al., 2001). Thus it may be useful to investigate tryptophan fluorescence to monitor molecular level interactions in process cheese.

Traditional right-angle fluorescence spectroscopic techniques cannot be applied to thick substances, especially food substances, due to large absorbance and scattering of light (Genot et al., 1992). However, Parker (1968) developed a technique to reduce the scattering effect by changing the angle of incidence onto the sample from $90^{\circ}$ to $56^{\circ}$. This technique is known as frontface fluorescence spectroscopy (FFFS) and is reported to provide information at the molecular level for gels that exhibit different rheological properties (Herbert et al., 1999). This technique has been successfully applied to other dairy products including milk and yogurt (Dufour and Riaublanc, 1997; Herbert et al., 1999). It has also been used to predict the melt characteristics of natural cheese (Karoui et al., 2003). However, no research has been done to apply this useful technique to predict process cheese functionality.

Tryptophan fluorescence spectra collected from a complex food product like process cheese cannot be interpreted using simple linear regression models because the spectra may consist of broad overlapping bands of various other substances present (Karoui et al., 2003), or is influenced by various quenching phe- nomena from the matrix. Additionally, the spectra contain more data points for analysis than the number of samples in the data set. Therefore to extract relevant information from the spectral data, a multivariate model is more appropriate and useful. Typically, multivariate statistical methods such as partial least square regression (PLS) are used to relate variations in the spectra to the functional properties of foods (Martens and Næs, 1989). The objective of the current study was to evaluate the feasibility of using fluorescence spectroscopy as a nondestructive technique to predict rheological characteristics of process cheese.

\section{MATERIALS AND METHODS}

\section{Cheese Samples}

Twenty-seven different process cheese spreads or products were obtained from 3 manufacturers. Nine samples (coded 1 to 9), 10 samples (coded 10 to 19), and 8 samples (coded 20 to 27) were obtained from manufacturers 1, 2, and 3 respectively. The fat content of all samples was determined using the Mojonnier method (Atherton and Newlander, 1977). Moisture content was determined using a vacuum oven method (Bradley and Vanderwarn, 2001) and protein content was determined using the Dumas method (Wiles et al., 1998). The $\mathrm{pH}$ was measured using a Corning $\mathrm{pH}$ /ion meter model 450 (Corning Glass Works, Medfield, MA) with a Sentron streamline $\mathrm{pH}$ probe (Sentron, Gig Harbor, WA).

\section{Dynamic Stress Rheometry}

Meltability of each process cheese spread or product was characterized using DSR, as described by Sutheerawattananonda and Bastian (1998) with some minor modifications. Blocks of cheese were cut from each sample, wrapped in Reynolds food service film (Nogg Chemical and Paper, Omaha, NE) to prevent moisture loss, and tempered to room temperature. A cylinder $(3 \mathrm{~mm}$ height $\times 25 \mathrm{~mm}$ diameter) was obtained from each block using a controlled thickness wire cutter and cork borer. The cylinder was then placed between serrated plates (25 mm diameter) in a dynamic stress rheometer (Rheometrics, Inc., Piscataway, NJ) and the dynamic rheological properties of the cheese were determined using a dynamic temperature ramp test. The frequency was set at $5 \mathrm{rad} / \mathrm{s}$, strain was 0.4 to $0.8 \%$, stress was $6300 \mathrm{~Pa}$, and the temperature was increased from 25 to $85^{\circ} \mathrm{C}$ at a rate of $10^{\circ} \mathrm{C} / \mathrm{min}$. To prevent moisture loss during heating, silicone oil (Dow Corning Corporation, Midland, MI) with viscosity of $5000 \mathrm{cP}$ was applied around the edges of the loaded sample. The values of $\mathrm{G}^{\prime}$ (storage modulus), $\mathrm{G}^{\prime \prime}$ (loss modulus), and $\tan \delta$ (loss 
tangent) were obtained. Previous researchers have shown that meltability index, determined as the lowest temperature at which $\tan \delta=1$ (a temperature when $\mathrm{G}^{\prime}$ was equal to $\mathrm{G}^{\prime \prime}$ ) correlates well with the Tube melt test and RVA melt test and can be used as a measure of process cheese spread functionality (Prow and Metzger, 2004). Therefore, $\tan \delta=1$ values were obtained for all the samples and are referred to as DSR values. Analysis was replicated twice on each sample and the average values were taken.

\section{Fluorescence Spectroscopy}

Three slices (5 mm thick) were obtained from the center of each block of process cheese spread or product using a controlled thickness wire cutter. Two discs (5 $\mathrm{mm}$ thick $\times 18 \mathrm{~mm}$ diameter) were drawn from each slice (a total of 6 discs) using a cork borer. The discs were then wrapped in Reynolds food service film (Nogg Chemical and Paper) to prevent moisture loss. The wrapped discs were tempered to $20 \pm 1^{\circ} \mathrm{C}$ before analysis. Each disc was individually loaded into a powder cell fitted with a quartz window. The cell was then mounted on a front-face accessory fitted to Perkin-Elmer LS50B spectrometer (Perkin-Elmer Ltd., Beaconsfield, UK), such that the incidence angle of excitation onto the cell was $56^{\circ}$ (Genot et al., 1992). Fluorescence spectra from each disc were obtained using FLDM software (Perkin-Elmer Ltd.). Six scans were performed on each disc, to record the emission spectra of tryptophan (305 to $400 \mathrm{~nm}$ ) at an excitation wavelength of $290 \mathrm{~nm}$ (a total of 190 points, each separated by 0.5 $\mathrm{nm})$. The slit widths were set at 9.0 and $4.0 \mathrm{~nm}$ for excitation and emission, respectively, and a $2 \%$ attenuation filter was used at the excitation slit.

\section{Mathematical Evaluations}

Multivariate analysis. Preprocessing of the spectral data included averaging 36 scans $(6$ scans from 6 discs) from each sample, normalizing by reducing the area under each curve to unity as described by Bertrand and Scotter (1992); and mean centering such that the average of all the spectra in the training set was subtracted from each spectrum. Preprocessed spectral data collected from the 27 samples was analyzed using PLS analysis (Martens and Næs, 1989). Partial least square regression is a multivariate statistical tool and was used to build a linear model between the functional or compositional data and spectral data. All the analysis was carried out using GRAMS 32AI (Galactic Industries Corp., Salem, NH). Three separate PLS models (using the tryptophan spectra and DSR values, tryptophan spectra and moisture content, and tryptophan

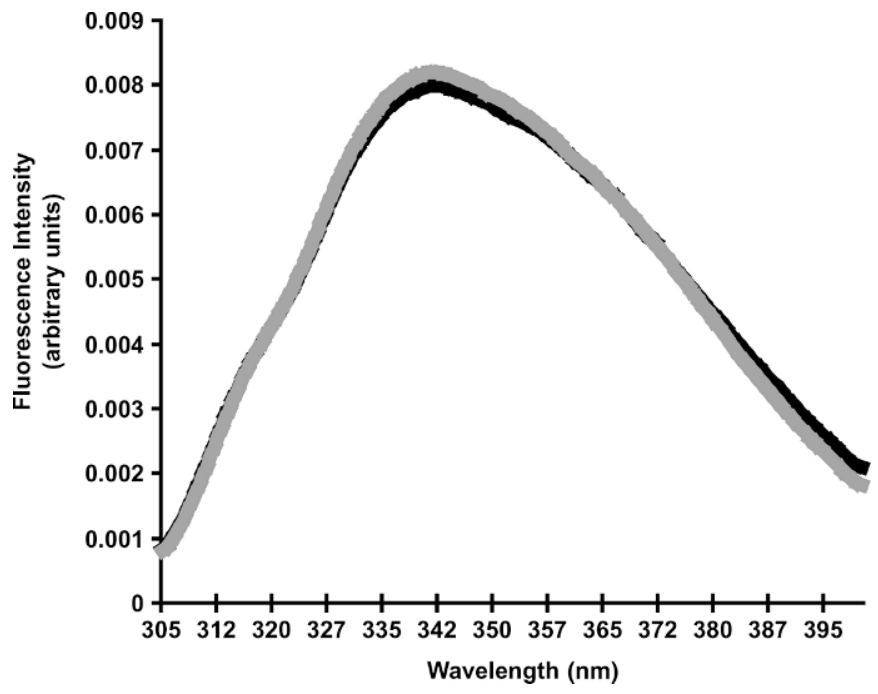

Figure 1. Fluorescence emission spectra of process cheeses samples 2 and 19. Emission is measured from 305 to $400 \mathrm{~nm}$ with excitation set at $290 \mathrm{~nm}$. Overlaid view of sample no. 2 (-) and sample no. $19(-)$ is shown.

spectra and protein content) were constructed by calculating PLS factors as linear combinations of spectral variations. The best prediction of DSR values, fat content, or protein content from the spectral data were arranged in decreasing order of the PLS factors, where the first few PLS factors contain relevant information for prediction and the subsequent factors account for noise. Partial least square regression modeling was done using a leave-one-out cross-validation method in which 27 submodels were built leaving each sample out once, and a full model with all the samples. The submodels were then used to compute residuals of each sample by evaluating them against the full model. The relevant factors used to build a prediction model were obtained by plotting the prediction residual error sum squares (PRESS) vs. the number of PLS factors, such that the lowest PRESS value was obtained using the least number of factors. Subsequently, samples that had large studentized $t$-residuals were identified as outliers and were eliminated from the training set. A final prediction model was then developed using the remaining samples, using the same methodology described above.

\section{RESULTS AND DISCUSSION}

\section{Physicochemical Characterization of Cheeses}

The results for moisture, fat, protein, $\mathrm{pH}$, and $\mathrm{DSR}$ values for each sample in the data set as well as the mean values for all samples from each manufacturer are reported in Table 1. Within the entire data set there 
Table 1. Composition and meltability index [dynamic stress rheometry (DSR) values] of process cheese spread/product samples from 3 manufacturers.

\begin{tabular}{|c|c|c|c|c|c|c|}
\hline Manufacturer & $\begin{array}{l}\text { Sample } \\
\text { number }\end{array}$ & $\begin{array}{l}\text { Moisture, } \\
\%\end{array}$ & $\begin{array}{l}\text { Fat, } \\
\%\end{array}$ & $\begin{array}{l}\text { Protein, } \\
\%\end{array}$ & $\mathrm{pH}$ & $\begin{array}{l}\text { DSR, } \\
{ }^{\circ} \mathrm{C}\end{array}$ \\
\hline 1 & 1 & 46.9 & 21.7 & 16.8 & 5.84 & 63.9 \\
\hline 1 & 2 & 46.5 & 21.6 & 16.8 & 5.82 & 67.0 \\
\hline 1 & 3 & 45.9 & 20.8 & 17.5 & 5.89 & 64.7 \\
\hline 1 & 4 & 46.0 & 21.4 & 17.3 & 5.89 & 62.7 \\
\hline 1 & 5 & 45.3 & 21.9 & 16.1 & 5.85 & 56.7 \\
\hline 1 & 6 & 45.3 & 21.9 & 16.5 & 5.81 & 68.4 \\
\hline 1 & 7 & 45.1 & 21.9 & 16.6 & 5.83 & 65.8 \\
\hline 1 & 8 & 46.9 & 22.0 & 16.2 & 5.83 & 65.1 \\
\hline 1 & 9 & 46.1 & 22.0 & 16.2 & 5.85 & 60.9 \\
\hline Man 1 & Mean & 46.0 & 20.7 & 16.7 & 5.84 & 65.5 \\
\hline 2 & 10 & 49.1 & 21.9 & 16.0 & 6.05 & 52.3 \\
\hline 2 & 11 & 47.8 & 22.3 & 16.0 & 5.91 & 55.7 \\
\hline 2 & 12 & 48.7 & 21.2 & 16.4 & 5.88 & 55.7 \\
\hline 2 & 13 & 49.7 & 21.5 & 15.7 & 6.04 & 51.3 \\
\hline 2 & 14 & 49.7 & 21.1 & 15.6 & 5.96 & 49.8 \\
\hline 2 & 15 & 50.0 & 21.95 & 15.6 & 5.98 & 49.0 \\
\hline 2 & 16 & 49.8 & 21.0 & 15.5 & 6.05 & 49.7 \\
\hline 2 & 17 & 50.2 & 20.5 & 15.4 & 5.89 & 49.0 \\
\hline 2 & 18 & 47.5 & 20.8 & 15.7 & 5.78 & 48.8 \\
\hline 2 & 19 & 47.8 & 20.8 & 15.5 & 6.08 & 47.7 \\
\hline Man 2 & Mean & 49.0 & 21.3 & 15.7 & 5.96 & 50.9 \\
\hline 3 & 20 & 46.9 & 23.8 & 17.5 & 5.83 & 64.7 \\
\hline 3 & 21 & 47.0 & 22.9 & 18.1 & 5.83 & 65.3 \\
\hline 3 & 22 & 46.2 & 22.6 & 17.7 & 5.83 & 63.9 \\
\hline 3 & 23 & 46.2 & 23.2 & 17.2 & 5.74 & 64.8 \\
\hline 3 & 24 & 47.5 & 22.7 & 17.7 & 6.05 & 57.2 \\
\hline 3 & 25 & 48.2 & 22.8 & 17.4 & 5.76 & 56.1 \\
\hline 3 & 26 & 47.6 & 22.2 & 17.6 & 5.76 & 59.4 \\
\hline 3 & 27 & 47.5 & 21.3 & 17.7 & 5.65 & 65.5 \\
\hline Man 3 & Mean & 47.2 & 22.7 & 17.6 & 5.81 & 62.1 \\
\hline
\end{tabular}

was a wide range in moisture, fat, protein, $\mathrm{pH}$, and DSR, and the values obtained ranged from 45.1 to $50.2 \%, 20.5$ to $23.8 \%, 15.4$ to $18.1 \%, 5.65$ to 6.08 , and 47.7 to $68.4^{\circ} \mathrm{C}$, respectively. The range of these values in the data set encompassed the normal range expected in process cheese spread or product. This range in composition and DSR values in the data set indicate that the data set is adequate for constructing a PLS-based calibration model. However, there were differences in composition and DSR values between the manufacturers. As an example, the mean moisture content of the samples from manufacturer 2 was higher and the DSR values were lower compared with samples from manufacturer 1 or 3. A simple linear regression analysis was performed to determine if the DSR values in the data set were correlated to compositional data. The results of this analysis are shown in Table 2. The DSR data had a correlation of 0.79 and 0.73 with moisture and protein respectively. The correlation of moisture and protein with DSR values is a concern because fluorescence data could simply be correlated to the moisture or protein, which are collinear to the DSR data. Consequently, any correlation with DSR data needs to be interpreted with caution. To address this issue we also used multivariate analysis to determine if fluorescence data was correlated with moisture or protein.

\section{Interpretation of the Fluorescence Spectra}

Tryptophan emission spectra were collected from all the samples, and were preprocessed as discussed earlier. An overlaid view of unit area normalized spectra from samples 2 and 19 is reported in Figure 1. There was a small difference in the moisture and fat content of these 2 samples (Table 1), however the DSR values were 67.0 and $47.7^{\circ} \mathrm{C}$ for sample 2 and 19 , respectively. Small differences in the peak intensity $\left(\mathrm{I}_{\mathrm{MAX}}\right)$ as well as the wavelength corresponding to maximum intensity $\left(\lambda_{\mathrm{MAX}}\right)$ are observed. Interestingly, sample 2 had a lower

Table 2. Correlation between physicochemical properties of process cheese spread/product samples $(n=27)$.

\begin{tabular}{lllll}
\hline Constituent & Fat & Protein & $\mathrm{pH}$ & $\mathrm{DSR}^{1}$ \\
\hline Moisture & 0.32 & 0.52 & 0.51 & 0.79 \\
Fat & & 0.58 & 0.27 & 0.46 \\
Protein & & & 0.53 & 0.73 \\
pH & & & 0.63 \\
\hline
\end{tabular}

${ }^{1}$ DSR $=$ Dynamic stress rheometry. 


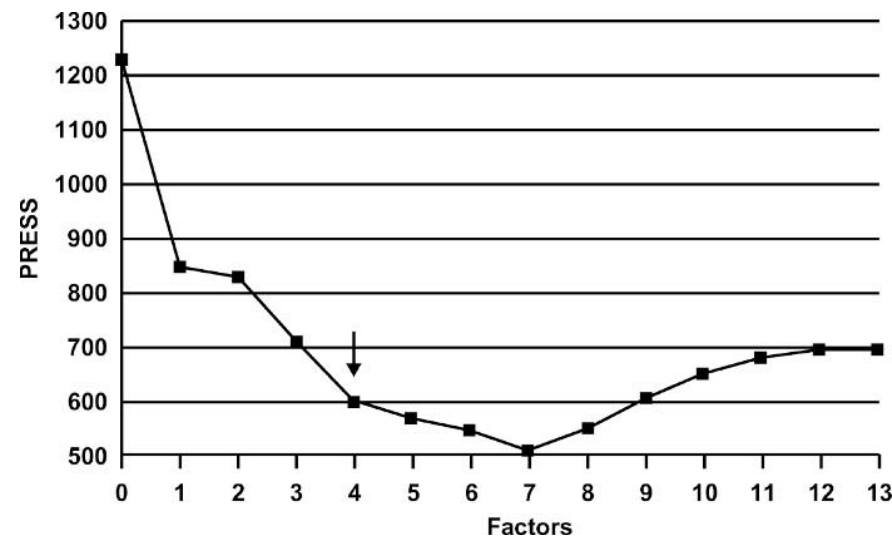

Figure 2. Partial least squares modeling with 27 samples and 13 factors: A prediction error residual sum of squares (PRESS) plot for a cross-validation prediction of a training set of tryptophan fluorescence spectra of 27 samples of process cheese. The slope indicates the contribution of the factor and the arrow indicates relevant number of factors.

$\mathrm{I}_{\mathrm{MAX}}$ and lower $\lambda_{\mathrm{MAX}}$ value, with its intensity being 0.007987 and $\lambda_{\operatorname{MAX}}$ at $341.5 \mathrm{~nm}$, whereas sample 19 had a higher $\mathrm{I}_{\operatorname{MAX}}(0.008185)$ and a red shift in the $\lambda_{\operatorname{MAX}}$ (342 nm).

Because the observed differences in the spectra of the samples were small and the number of wavelengths in the spectra is larger than the number of samples in the data set, it was necessary to analyze the data set using multivariate statistical techniques. Partial least squares regression, a common multivariate statistical technique, was used to correlate spectral changes to DSR.

\section{PLS Analysis}

In PLS analysis, factors are computed as linear combinations of spectral variations. The optimum number of factors used in the model was determined by conducting a cross-validation analysis. The PRESS plot obtained is shown in Figure 2. The results of this plot indicate that a model using 4 factors was appropriate for predicting DSR melt temperature from the tryptophan fluorescence spectral data. Subsequently a plot of the studentized $t$-residual for each sample was constructed using the 4-factor model and is shown in Figure 3 . This plot was used to identify samples that were outliers in the data set. Samples 6, 14, and 27 had studentized $t$-values greater than 1.96 (95\% confidence interval) and were identified as outliers. Upon closer inspection of these samples, sample 6 had a DSR value of $68.3^{\circ} \mathrm{C}$, which was the highest within manufacturer 1 , and sample $27 \mathrm{had}$ a DSR value of $65.5^{\circ} \mathrm{C}$, which was highest within samples from manufacturer 3 . However, there was no indication as to why sample 14 was an

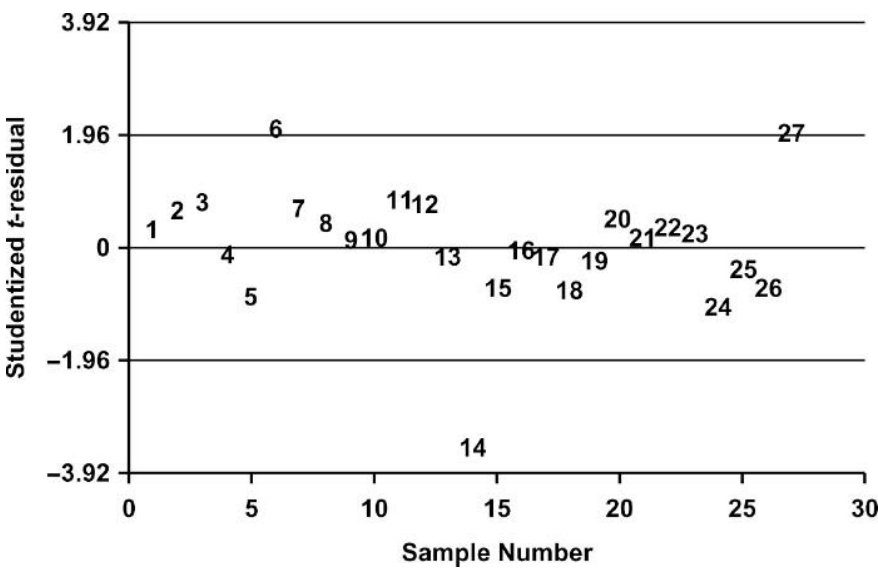

Figure 3. A plot of Studentized $t$-residuals vs. sample number for a cross-validation prediction of a training set of tryptophan fluorescence spectra of 27 samples of process cheese. Samples 6, 14, and 27 ( $\mathrm{t}>$ 1.96) were detected as outliers.

outlier. These 3 samples were eliminated from the data set and a new PLS prediction model was built using the remaining samples. The PRESS plot obtained is shown in Figure 4, and it indicated that 5 factors should be used in the model. Subsequently, studentized $t$-residuals were obtained for all the samples and it was observed that all the samples had studentized $t$-residuals within the $95 \%$ confidence interval (data not shown). A plot of actual vs. predicted values was then constructed for the full model and the model with outliers removed and is shown in Figure 5. A multivariate correlation coefficient of 0.85 was obtained for the full model and a correlation coefficient of 0.93 was obtained for the model with outliers removed. These results suggest that the DSR values can be predicted using FFFS analy-

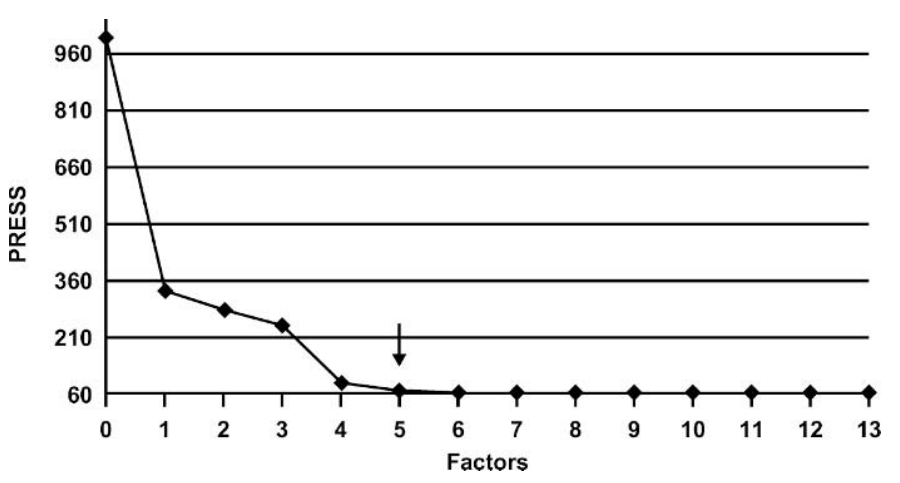

Figure 4. Partial least squares modeling with 24 samples and 13 factors: A prediction error residual sum of squares (PRESS) plot for a cross-validation prediction of a training set of tryptophan fluorescence spectra of 24 samples of process cheese (outliers excluded). The slope indicates the contribution of the factor and the arrow indicates relevant number of factors. 
A

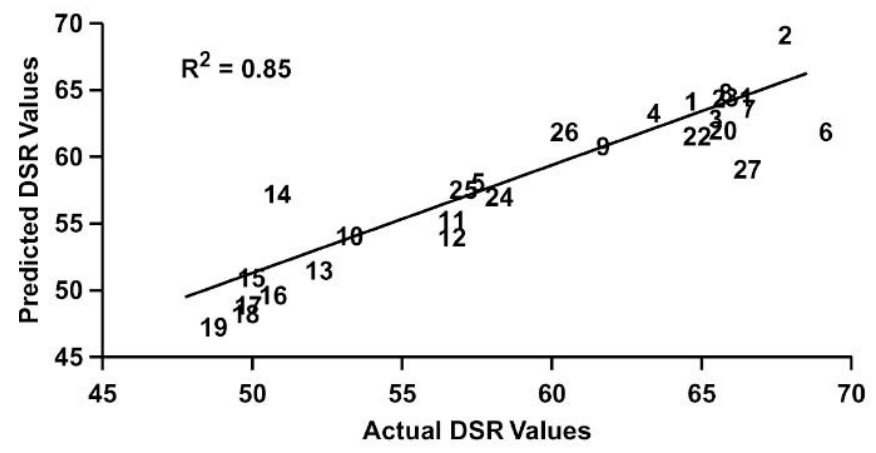

B

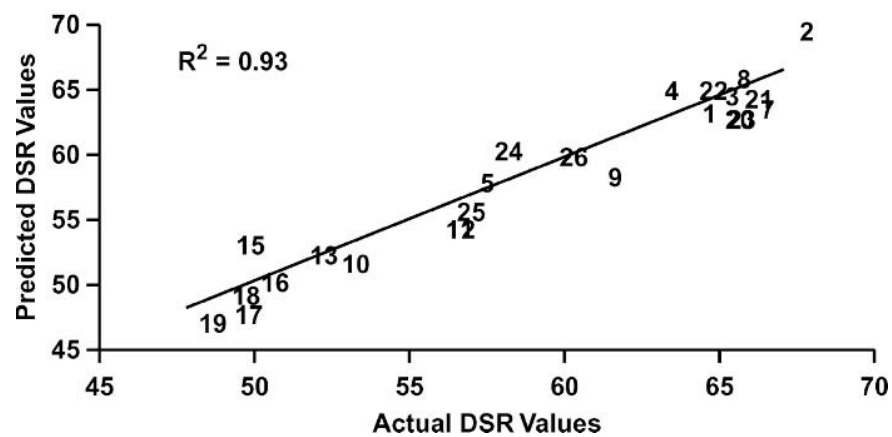

Figure 5. Partial least squares prediction model: Actual vs. Predicted dynamic stress rheometry (DSR) values plot for a cross-validation prediction of a training set of tryptophan fluorescence spectra; for the 4-factor model for the entire data set (A); and for 5-factor model with 3 outliers removed (B).

sis of tryptophan. However, as discussed earlier, there were high correlations between moisture content and DSR values, as well as between protein content and DSR values. Therefore, separate PLS models were constructed to check the correlations between FFFS data and moisture or protein content. A plot of the actual vs. predicted values for the full model and the model with outliers removed for moisture and protein content are shown in Figures 6 and 7, respectively. The correlation coefficients obtained for the entire data set were 0.63 and 0.70 for moisture and protein, respectively. In both the moisture and protein data numerous outliers were detected, and 9 and 6 samples had to be removed from the moisture and protein data sets, respectively, to construct the PLS models. The correlation coefficients for the PLS models with the outliers removed was 0.93 and 0.88 for moisture and protein, respectively. The higher correlation and more robust model for the FFFS spectral data and DSR values support our theory that FFFS data may be used to measure the emulsion characteristics and functionality of process cheese.
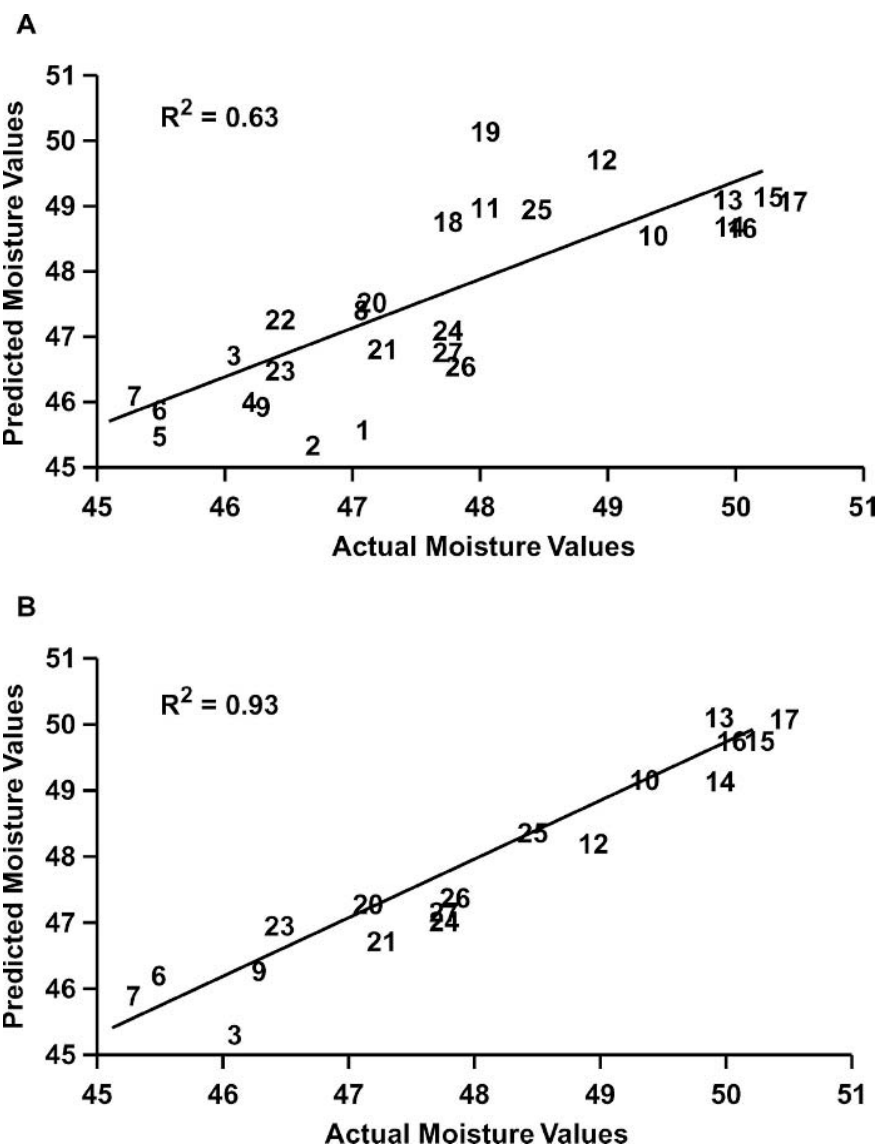

Figure 6. Partial least squares prediction model: Actual vs. Predicted moisture values plot for a cross-validation prediction of a training set of tryptophan fluorescence spectra; for the 5-factor model for the entire data set (A); and for the 4 -factor model with 9 outliers removed (B).

\section{Theoretical Relationship Between Tryptophan Fluorescence and Process Cheese Emulsion Characteristics}

To gain fundamental information on how tryptophan fluorescence is related to the emulsion characteristics of process cheese spread or product, a correlation coefficient vs. wavelength was constructed (Figure 8). This plot can be used to identify the regions of spectra that are correlated to DSR values. The spectral region from 335 to $350 \mathrm{~nm}$ was negatively correlated with the DSR values. This negative correlation indicates that a decrease in tryptophan emission occurs with an increase in the DSR values. The chemistry behind this correlation can be explained by the environment-sensitive characteristics of tryptophan. Previous researchers have demonstrated that the emission spectra of tryptophan residues change with the movement of tryptophan residues to a hydrophobic environment. As an example $\lambda_{\text {MAX }}$ of approximately $350 \mathrm{~nm}$ typically characterizes 


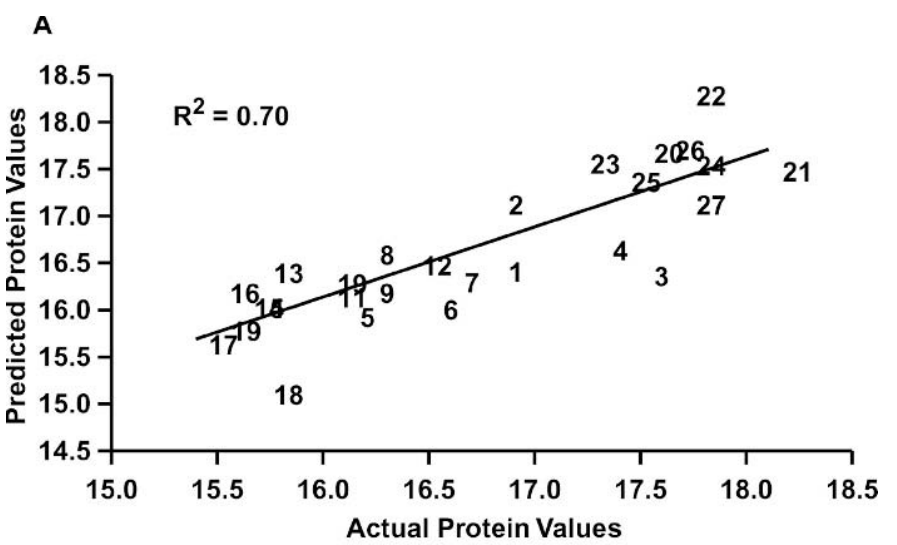

B

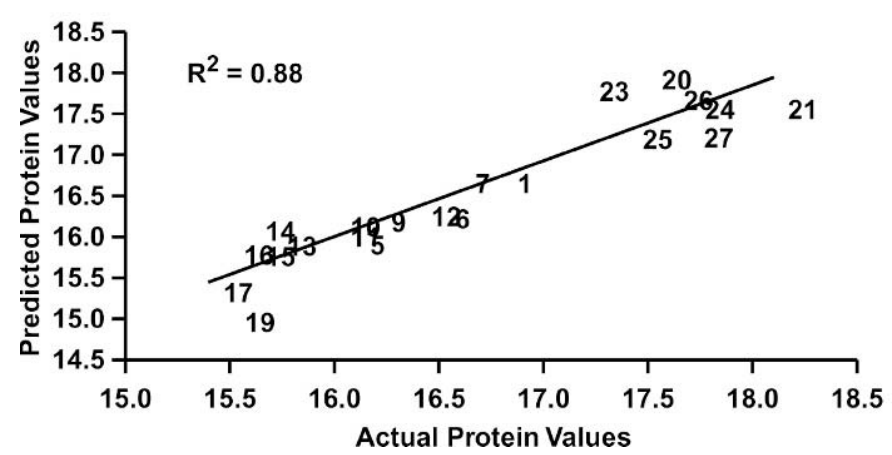

Figure 7. Partial least square regression prediction model: Actual vs. Predicted protein values plot for a cross-validation prediction of a training set of tryptophan fluorescence spectra; for the 2-factor model for the entire data set (A); and for 3 -factor model with 6 outliers removed (B).

tryptophan emission spectrum in a polar environment, whereas it is marked by a blue shift (decrease in $\lambda_{\operatorname{MAX}}$ ) in the hydrophobic core of proteins (Lackowicz, 1983). Additionally, in emulsions the movement of tryptophan from a polar environment to a nonpolar environment

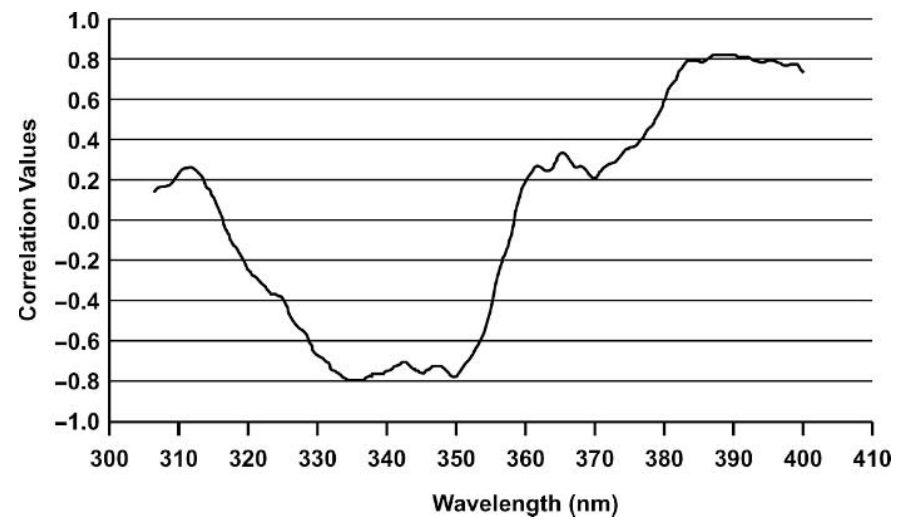

Figure 8. Correlation coefficient (R) of tryptophan fluorescence spectra of 24 samples of process cheese (outliers excluded). is indicated by a decrease in the $\lambda_{\operatorname{MAX}}$ (wavelength of maximum intensity) as well as in the $\mathrm{I}_{\mathrm{MAX}}$ (maximum intensity) (Rampon et al., 2003). Because process cheese is an emulsion stabilized by protein (primarily casein), during process cheese manufacture, the hydrophobic sections of partially dissociated casein interact with fat and hydrophilic regions interact with water (Marchesseau and Cuq, 1995; Ennis et al., 1998; Lee et al., 2003). Consequently, the characteristics of process cheese may be related to the fluorescence properties of tryptophan. As an example, a strong emulsion is formed due to increased interactions between protein and fat and is characterized by a uniform distribution of small fat globules, whereas a weak emulsion has minimal interactions between fat and protein (Caric et al., 1985; Awad et al., 2002). Consequently, the state of a process cheese emulsion will influence the environment of tryptophan, such that tryptophan residues in stronger emulsions are surrounded by more fat molecules and are therefore in a more hydrophobic environment compared with tryptophan residues in weaker emulsions. A strong emulsion results in a decrease in process cheese meltability (Glenn et al., 2003). Therefore, the emission spectra of tryptophan in samples with higher DSR values should have lower $\mathrm{I}_{\text {MAX }}$ and $\lambda_{\text {MAX }}$ values compared with samples with lower DSR values. This explanation is in agreement with our findings and supports the theory that the movement of tryptophan residues to a more hydrophobic environment occurs as emulsion strength is increased. It was also noted that the spectral region from 385 to $400 \mathrm{~nm}$ was positively correlated with the DSR values indicating that broadening of the curve occurs with an increase in the emulsion strength.

\section{CONCLUSIONS}

This study demonstrated that FFFS, coupled with multivariate statistical methods, could be used as a noninvasive technique to predict the functional properties of process cheese spreads or products. The fluorescence spectra of tryptophan were highly correlated to the cheese meltability index as measured using DSR. This correlation may be related to changes in the environment of tryptophan as a result of the state of the emulsion present in process cheese. The large range in functionality of the cheeses included in the data set indicate that FFFS analysis can be applied to wide range of process cheese spread samples. However, a further study with samples of controlled formulation and processing parameters would be useful.

\section{ACKNOWLEDGMENTS}

The authors would like to thank Midwest Dairy Association Inc. for funding this work. 


\section{REFERENCES}

Arnott, D. R., H. A. Morris, and W. B. Combs. 1957. Effect of certain chemical factors on the melting quality of process cheese. J. Dairy Sci. 40:957-963.

Atherton, H. V., and J. A. Newlander. 1977. Tests for fat: Babcock, Gerber, and Mojonnier. Pages 71-116 in Chemistry and Testing of Dairy Products. 4th ed. AVI Publ. Co. Inc., Westport, CT.

Awad, R. A., L. B. Abdel-Hamid, S. A. El-Shabraway, and R. K. Singh. 2002. Texture and microstructure of block type processed cheese with formulated emulsifying salt mixtures. Lebensm.-Wiss. U.Technol. 35:54-61.

Berger, W., H. Klostmeyer, K. Merkenich, and G. Uhlmann. 1998 Process Cheese Manufacture-A JOHA Guide. BK Guilini Chemie Gmbh \& Co. OHG, Ladenberg, Germany.

Bertrand, D., and C. N. G. Scotter. 1992. Application of multivariate analyses to NIR spectra of gelatinized starch. Appl. Spectrosc. 46:1420-1425.

Bradley, R. L., Jr., and M. A. Vanderwarn. 2001. Determination of moisture in cheese and cheese products. J. AOAC Int. 84:570-592.

Caric, M., M. Gantar, and M. Kalab. 1985. Effects of emulsifying agents on the microstructure and other characteristics of process cheese-A review. Food Microstruct. 4:297-312.

Dufour, E., and A. Riaublanc. 1997. Potentiality of spectroscopic methods for characterization of dairy products. I. Front-face fluorescence study of raw, heated and homogenized milks. Lait 77:657-670.

Ennis, M. P., M. M. O'Sullivan, and D. M. Mulvihill. 1998. The hydration behaviour of rennet caseins in calcium chelating salt solution as determined using a rheological approach. Food Hydrocoll. $12: 451-457$

Fox, P. F. 1989. The milk protein system. Pages 1-54 in Developments in Dairy Chemistry. 4. Functional milk proteins. P. F. Fox, ed. Elsevier Appl. Sci., New York, NY.

Fox, P. F., and D. M. Mulvihill. 1990. Pages 121-173 in Food Gels: Casein. P. Harris, ed. Elsevier Appl. Sci., London, UK.

Genot, C., F. Tonetti, T. Montenay-Garestier, D. Marion, and R. Drapon. 1992. Front-face fluorescence applied to structural studies of proteins and lipid-protein interactions of visco-elastic food products. 2. Application of wheat gluten. Sci. Aliments 12:687-704.

Glenn III, T. A., C. R. Daubert, B. E. Farkas, and L. A. Stefanski. 2003. A statistical analysis of creaming variables impacting process cheese melt quality. J. Food Qual. 26:299-321.

Gupta, S. K., C. Karahdian, and R. C. Lindsay. 1984. Effect of emulsifier salts on textural and flavor properties of processed cheeses. J. Dairy Sci. 67:764-778.

Herbert, S., A. Riaublanc, B. Bouchet, D. J. Gallant, and E. Dufour. 1999. Fluorescence spectroscopy investigation of acid- and rennetinduced coagulations of milk. J. Dairy Sci. 82:2056-2062.

Karoui, R., A. Laguet, and E. Dufour. 2003. Fluorescence spectroscopy: A tool for the investigation of cheese melting-correlation with rheological characteristics. Lait 83:251-264.
Kosikowski, F. V., and V. V. Mistry. 1997. Process cheese and related products. Pages 156-161 in Cheese and Fermented Milk Foods. Vol. 2. 3rd ed. F. V. Kosikowski, LLC, Westport, CT.

Lackowicz, J. R. 1983. Protein Fluorescence. Pages 341-389 in Principles of Fluorescence Spectroscopy. J. R. Lackowicz, ed. Plenum Press, New York, NY.

Lee, S. K., R. J. Buwalda, S. R. Euston, E. A. Foegeding, and A. B. McKenna. 2003. Changes in the rheology and microstructure of process cheese during cooking. Lebensm.-Wiss. U.-Technol. 36:339-345.

Marchesseau, S., and J.-L. Cuq. 1995. Water-holding capacity and characterization of protein interactions in processed cheese. J. Dairy Res. 62:479-489.

Martens, H., and T. Næs. 1989. Multivariate Calibration. John Wiley and Son, London, UK.

Mazerolles, G., M. F. Devaux, G. Duboz, M. H. Duployer, N. Mouhous Riou, and E. Dufour. 2001. Infrared and fluorescence spectroscopy for monitoring protein structure and interaction during cheese ripening. Lait 81:509-527.

Muthukumarappan, K., Y.-C. Wang, and S. Gunasekaran. 1999. Estimating softening point of cheeses. J. Dairy Sci. 82:2280-2286.

Nolan, E. J., J. J. Shieh, and V. H. Holsinger. 1990. A comparison of some rheological properties of cheddar and pasteurized process American cheese. Pages 370-379 in Engineering and Food, Vol. 1, Physical properties and process control. W. E. L. Spiess, and W. Schubert, ed. Elsevier Appl. Sci., New York, NY.

Olson, N. F., and W. V. Price. 1958. A melting test for pasteurized process cheese spreads. J. Dairy Sci. 41:999-1000.

Parker, C. A. 1968. Apparatus and experimental methods. Pages 128-302 in Photoluminescence of solutions with applications to photochemistry and analytical chemistry. C. A. Parker, ed. Elsevier, Amsterdam, The Netherlands.

Prow, L. A., and L. E. Metzger. 2004. Evaluation of process cheese meltability using rapid visco analyzer. J. Dairy Sci. 87(Suppl. 1): 418

Rampon, V., C. Genot, A. Riaublanc, M. Anton, M. A. V. Axelos, and D. J. McClements. 2003. Front-face spectroscopy study of globular proteins in emulsions: Displacement of BSA by a nonionic surfactant. J. Agric. Food Chem. 51:2482-2489.

Ryan, A. A., M. Kalab, and C. A. Ernstrom. 1980. Microstructure of process cheese. Scan. Electron Microsc. III:635-643.

Sutheerawattananonda, M., and E. D. Bastian. 1998. Monitoring process cheese meltability using dynamic stress rheometry. J. Texture Stud. 29:169-183.

Thomas, M. A. 1973. The Manufacture of Processed Cheese - Scientific Principles. 1st ed. New South Wales Department of Agriculture, Richmond, NSW, Australia.

Ustunol, Z., K. Kawachi, and J. Steffe. 1994. Arnott test correlates with dynamic rheological properties for determining Cheddar cheese meltability. J. Food Sci. 59:970-971.

Wiles, P. G., I. K. Gray, and R. C. Kissling. 1998. Routine analysis of proteins by Kjeldahl and Dumas methods: Review and interlaboratory study using dairy products. J. AOAC Int. 81:620-632. 